\title{
O enfrentamento ao conservadorismo no Serviço Social a partir das campanhas do CFESS/CRESS
}

\author{
The Confrontation with Conservatism in Social Work from the CFESS/CRESS
}

\author{
Clara MARTINS DO NASCIMENTO 1 \\ CLAudio HenRiQue Miranda Horst (102 \\ ${ }^{1}$ Universidade Federal de Santa Catarina, Florianópolis, SC, Brasil. \\ ${ }^{2}$ Universidade Federal de Ouro Preto, Mariana, MG, Brasil.
}

RESUMO - Este artigo recupera a estratégia de enfrentamento ao conservadorismo no Serviço Social a partir das campanhas comemorativas do dia do Assistente Social, lançadas pelo conjunto CFESS/CRESS nos anos de 2017 e 2018. Resgata, para tanto, as expressões empíricas desse conservadorismo representadas no avanço de práticas sistêmicas no exercício profissional. Considera que os motes das referidas campanhas ao denunciarem o conservadorismo, possuem pertinência histórica correspondente ao estágio atual da luta de classes no Brasil - momento fecundo para a resistência dos trabalhadores.

Palavras-chave: Serviço Social. Luta de classes. Projeto Ético-Político. Conservadorismo. CFESS/CRESS.

ABSTRACT - This article recovers the strategy of coping with Social Work conservatism based on the commemorative campaigns of the Social Worker's Day, launched by the CFESS/CRESS group in 2017 and 2018. It rescues, therefore, the empirical expressions of this conservatism represented in the advance of practice in practice. It considers that the mottoes of the campaigns to denounce the conservatism, have historical pertinence corresponding to the current stage of the class struggle in Brazil - fecund moment for the resistance of the workers.

Keywords: Social Work. Class struggle. Ethical-political Project of Social Work. Conservatism. CFESS/CRESS. 


\section{Introdução}

ob o lema "Na luta de classes não há empate: Assistente Social, profissional em defesa das liberdades democráticas e dos direitos sociais" e "Nossa escolha é a resistência: somos classe trabalhadora" as campanhas do dia do Assistente Social, lançada pelo Conjunto CFESS/CRESS ${ }^{1}$ nos anos de 2017 e 2018, mobilizaram a categoria a refletir acerca da sua intervenção profissional na atual conjuntura. Este artigo elucida, a partir da análise dos materiais das referidas campanhas, dois principais movimentos de enfrentamento ao conservadorismo profissional: a) a necessidade do fortalecimento da concepção de classe no âmbito do Serviço Social; e b) o esforço das entidades representativas, de atribuir direção às respostas profissionais frente ao avanço do conservadorismo. Conclui sobre a correspondência dos motes das campanhas com a particularidade deste tempo histórico, ratificando o estreitamento da profissão com as mais significativas bandeiras de luta da classe trabalhadora.

A conjuntura que sedimenta o material das campanhas é conformada pelos impactos deletérios das contrarreformas integrantes da agenda restauradora proposta pelo capital rentista que avançam no cenário de crise e restauração do capital. Mais especificamente, as implicações desse cenário na alteração das demandas e respostas profissionais dos Assistentes Sociais. O seu conteúdo chama atenção para o acirramento da chamada "questão social" brasileira (demarcada pela exploração brutal da classe trabalhadora, pelo crescimento do desemprego, a violência policial contra os negros, pobres, a violência contra a mulher, o sucateamento/precarização das parcas e focalizadas políticas sociais) ${ }^{2}$ conclamando a categoria a defender e avançar na consolidação do seu Projeto Ético-Político (PEP) comprometido com os interesses da classe trabalhadora ${ }^{3}$.

$\mathrm{Na}$ análise do conteúdo dos materiais produzidos pelo conjunto CFESS/CRESS para as respectivas campanhas, o chamamento à perda das ilusões conciliatórias entre as personificações do capital e do mundo do trabalho emerge como alternativa fundamental a ser incorporada pelo projeto coletivo profissional. Neste aspecto, uma possível renovação da esquerda, dos sindicatos, dos intelectuais comprometidos em vocalizar os interesses das classes subalternas e, inclusive, os Assistentes Sociais aparecem como iniciativas que podem resultar das contradições engendradas nesse cenário (CFESS, 2017).

As Campanhas também ressaltam o fato de que este tempo histórico exige da capacidade profissional de particularizar as tendências universalizantes e apreender as suas expressões mais concretas singularizadas na realidade dos espaços sócio-ocupacionais. Ou seja, os limites e as possibilidades de avanço na materialização de uma atuação profissional mediada pelo PEP - a partir da análise concreta de situações concretas - exigem capacidade de apreender as mediações que nos levam a uma intervenção cada vez mais crítica.

Esta dimensão contraditória engendrada pela atual ofensiva conservadora, que impacta os debates travados no âmbito do Serviço Social, é enfatizada nas campanhas em dois sentidos: a) Na reafirmação da existência da luta de classe e do seu caráter desigual - o desmoronamento das ilusões conciliatórias, e, b) na legitimação social do PEP, uma vez que a atual conjuntura elucida o estreitamento dos valores e princípios desse projeto com as bandeiras de luta dos/as trabalhadores/as. Assim, os motes do CFESS/CRESS constituem-se em um convite ao acirramento da luta contra o conservadorismo e a dominação de classe - uma convocação para uma tomada de partido na direção do fortalecimento da agenda de lutas da classe trabalhadora, coerente com o Projeto Ético-Político da categoria na atualidade.

\section{O Serviço Social e a luta de classes: se posicionar e resistir}

Neste cenário demarcado por uma crise de caráter estrutural do sistema metabólico do capital, que afeta todas as esferas da produção e reprodução social (MÉSZÁROS, 2009), promovendo um notório acirramento da "questão social"; redobram- se os desafios da categoria dos Assistentes Sociais em refletir o fazer profissional. O "[...] constante aprimoramento intelectual", já inscrito nos princípios do Código de ética (BRASIL, 2012), deverá, portanto, ser aprofundado e defendido no sentido de instrumentalizar a profissão a responder criticamente aos desafios da atualidade. 
Concebemos essa necessidade de uma constante atualização e aprofundamento teórico-metodológico fundamentado, hegemonicamente, nos preceitos da teoria social crítica, enquanto exigência de primeira ordem para o exercício profissional. Isto porque a crítica nos ajuda a desvelar os nexos causais mais intrínsecos entre as demandas emergentes, as respostas institucionais, a precarização dos serviços e condições de trabalho e a atual dinâmica de funcionamento do capitalismo brasileiro. Tal como foi enfatizado por Vasconcelos (2015, p. 20):

Nesse sentido, a teoria social crítica cumpre dois papeis na formação de profissionais dotados de pensamento radicalmente crítico e capacidade inventiva: a de iluminar corações e mentes no sentido de enfrentar a força do capital em cada um de nós $e$ como referência central de uma atividade profissional pensada, ou seja, planejada, propositiva e avaliada nas suas consequências, mais do que nos seus resultados, ainda que isso se torne, também, importante, tendo em vista apreender sua eficácia e eficiência na busca de materialização das suas finalidades e objetivos (VASCONCELOS, 2015, p. 20).

Não há dúvidas de que este seja um importante ponto de partida para o combate à disseminação de concepções psicologizantes - distanciadas de uma perspectiva de totalidade social. Tais concepções mobilizam elementos do positivismo e suas dissidências teóricas para justificar a culpabilização dos sujeitos por sua condição de vida.

Ao nosso ver, tal postura apresenta-se também enquanto alternativa de resposta à disseminação cotidiana, realizada pela grande mídia, de um discurso liberal que legitima a ofensiva conservadora materializada nas contrarreformas sociais ${ }^{4}$. Nesse sentido, destaca-se a centralidade do compromisso da categoria, previsto no PEP, de mobilizar e organizar a classe trabalhadora na defesa de seus direitos (ABREU; CARDOSO, 2009). Essa dimensão ético-política da profissão foi ressaltada pelas referidas campanhas do Conjunto CFESS/CRESS chamando atenção, inclusive, para a retomada dos trabalhos de base, no âmbito do Serviço Social (CFESS, 2017).

Faz-se urgente, portanto, o posicionamento profissional contra o teor e o conteúdo das contrarreformas em curso ${ }^{5}$, denunciando o lugar que eles ocupam na agenda do grande capital e do dimensionando à barbárie social que as mesmas provocam. Esta agenda restauradora, amplamente disseminada, de modo a constranger os trabalhadores a incorporarem os projetos da classe dominante como sendo seus, pode ser evidenciada, por exemplo, na apresentação elaborada pela Conferência Nacional da Industria (CNI) intitulada "Agenda para o Brasil sair da crise" (CNI, 2017). Esse documento condensa a avaliação de 36 propostas em evolução, nas áreas de "eficiência do Estado, tributação, relações de trabalho, infraestrutura, financiamento, comércio exterior, segurança jurídica e regulamentação e inovação" para a formação de um ambiente propício às transações rentistas. Nele, constam medidas deletérias à classe trabalhadora: "reformar a previdência", "implementar mecanismos de controle dos gastos públicos" e "regulamentar a terceirização" (CNI, 2017).

Não é preciso ressaltar que não há nada similar entre as reformas que foram defendidas no âmbito da esquerda (ainda que tivessem sido apontadas como limitadas, sob o ponto de vista da tática-estratégica de tomada de poder pela classe trabalhadora), com a atual orientação conservadora das "reformas" conduzidas pelo Estado brasileiro. No atual contexto, o termo reforma é ressignificado na condição de responder às necessidades do capital de restringir os gastos sociais, de restringir o acesso da classe trabalhadora aos serviços sociais, de implementar políticas de austeridade fiscal. Ou seja, suprimir os parcos direitos conquistados pela classe trabalhadora, inscritos na Constituição Federal de 1988. Partindo de tais pressupostos, a categoria que nos parece expressar bem o teor conservador destas medidas é a categoria da contrarreforma.

No âmbito do Serviço Social, uma vez que a atuação desses profissionais está orientada para responder à demanda das classes subalternas ao acesso a serviços e às políticas sociais, os mesmos enfrentam, diretamente, o impacto extremamente negativo das contrarreformas em curso. Convivem com a angústia resultante de um aumento desenfreado da demanda de nossos usuários (acirrada pelo rebaixamento das condições de vida) paralela à brutal precarização dos serviços públicos que, por sua vez, restringe a 
capacidade de resposta profissional. Isto porque a intervenção, de maneira geral, demanda condições concretas de efetivação: desde infraestrutura para recebimento dos usuários, como a própria abrangência de serviços, programas e projetos para inserção deles.

Outra questão central que emerge com grande força neste contexto contrarreformista diz respeito às possibilidades do exercício da "autonomia relativa" (IAMAMOTO, 2005) do Serviço Social, diante da generalização da precarização dos vínculos trabalhistas, da falta de estabilidade no trabalho e das condições de trabalho (incluindo-se também os servidores públicos). Nos municípios, por exemplo, essa situação é agravada pelas particularidades locais, perpassadas por correlações de forças na política que impulsionam, por exemplo, a renovação dos quadros profissionais a cada mudança de gestão. Tais condições históricas demandam que a categoria se posicione coletivamente, no sentido do seu enfrentamento. Nessa direção, conforme chamou-nos atenção Vasconcelos (2015, p. 243):

[...] a precarização do trabalho e as condições adversas de trabalho como próprias da sociedade do capital não se constituem em justificativa para a direção social que resulta dos serviços prestados, mas condições a serem enfrentadas no cotidiano da prática, como nos revela o próprio movimento da classe trabalhadora ao longo da história, na busca por sua emancipação.

Não nos parece que as respostas à crise estejam na conformação profissional diante da sua condição de trabalhador assalariado que, assim como os demais trabalhadores, vêm sofrendo o ataque aos seus direitos sociais. Contrariamente, as campanhas do Conjunto CFESS/CRESS tentam nos alertar para uma tomada de posição amparada na luta de classes, na defesa da liberdade e dos direitos sociais, em uma perspectiva de reafirmação do Projeto Ético-Político do Serviço Social.

Nesta direção, tais campanhas reafirmaram que a orientação para os esforços profissionais seja canalizada para o seu engajamento no cenário de efervescência política, sendo mais um sujeito coletivo a vocalizar os interesses da classe trabalhadora. Isto não significa desconsiderar que enquanto trabalhadores assalariados, o Serviço Social possui uma atuação limitada no espaço de trabalho. Não é possível nutrir ilusões de que os espaços sócio-ocupacionais sejam favoráveis às lutas de classe. Mas, a instrumentalidade profissional, mediada pelo PEP, abre um leque de possibilidades de vislumbrar e tencionar a construção de respostas críticas em uma perspectiva de classe.

É nesse intricado, complexo e conflituoso processo que o assistente social pode munir-se do necessário e formar-se/informar-se com qualidade, cuidado e em longo prazo, para que tenha condições de suportar as adversidades do cotidiano profissional, que envolvem, além das péssimas condições de trabalho, investidas alienantes e paralisantes, o que exige não só alianças necessárias com o que se põe na realidade imediata e mediata, mas estar atento e crítico frente às enganosas, capciosas e ilusórias facilidades dadas pela sociedade do capital para (des)organizar o cotidiano profissional e nos impedir de nos constituirmos como sujeitos da atividade profissional na direção social escolhida (VASCONCELOS, 2015, p. 235).

Ao compreendermos que "na luta de classe não há empate" e que "nossa escolha é a resistência: somos classe trabalhadora", ratificamos, portanto, a necessidade de refletirmos sobre a intervenção profissional do sentido do "[...] fortalecimento da identidade profissional e do reconhecimento das nossas atribuições e competências nos locais de trabalho" (CFESS, 2017). Nesta direção, a apropriação dos fundamentos teórico-metodológicos, ético-políticos e técnico-operativos da profissão, a própria instrumentalidade do Serviço Social - na perspectiva trabalhada por Guerra (2002) - constitui-se exigência para que a profissão vislumbre respostas críticas às tendências mundializadas do capital, nas suas expressões particulares do cotidiano profissional. Dessa forma, tal como inscrito no CFESS (2017), as campanhas sinalizam alternativas de atuação coletiva pautadas na/o:

a) democratização das informações no cotidiano e no atendimento direto junto aos usuários/as, explicitando a brutal redução do orçamento público para as políticas sociais e as medidas que se propõem a suprimir parcos direitos; 
b) retomada dos trabalhos de base;

c) articulação com organizações e movimentos sociais para adensar a luta junto aos demais trabalhadoras/es na defesa de direitos políticos, sociais, trabalhistas e de um projeto societário livre da exploração e diversas formas de opressão;

d) exigência de manifestação da categoria, a partir de suas entidades representativas, de posicionamentos contrários às normativas, resoluções que impliquem no sucateamento das políticas sociais e supressão de parcos direitos ${ }^{6}$.

As campanhas também enfatizam a impossibilidade de uma intervenção neutra pelos Assistentes Sociais (CFESS, 2017)7. Ademais, na campanha de 2018, observa-se o destaque para a questão racial e de gênero, remetendo a categoria a pensar as situações vivenciadas pela classe trabalhadora. Tal ênfase reafirma, inclusive, um elemento central da campanha, que buscou dialogar diretamente com outro princípio fundamental do código de ética, qual seja, a opção por um "projeto profissional vinculado ao processo de construção de uma nova ordem societária, sem dominação, exploração de classe, etnia e gênero" (BRASIL, 2012). A atuação direta com a classe trabalhadora (e, sendo parte dela) na gestão do acesso a serviços situa a história profissional em uma perspectiva de classe - já sinalizada nas produções teóricas elaboradas pelo coletivo profissional desde a década de 1970. Não há empate! Não há neutralidade! A classe trabalhadora disputa em condições desfavoráveis. Sabemos que a dinâmica própria do capital, desvelada por Marx a partir da Lei Geral da acumulação capitalista (MARX, 2013), não permite a socialização da riqueza social. Dela, somente resulta o aumento da pauperização da classe trabalhadora. Sobre esse aspecto, o posicionamento do CFESS (2017) foi sintetizado da seguinte forma:

[...] o trabalho de assistentes sociais não se desenvolve de forma neutra no contexto de uma sociedade de classes, que cotidianamente penaliza usuários/as com a desigualdade social, e em um país cujo ajuste estrutural do Estado resvala contra os direitos sociais conquistados pelos/as trabalhadores/as. Os princípios construídos pela profissão se materializam no cotidiano pelo reconhecimento de que temos um lado e de que, na sociedade de classes, não há empate (CFESS, 2017, p. 5).

Nesta perspectiva, o Serviço Social deve posicionar-se contra esses ataques conservadores e reafirmar, mediante o PEP, o seu compromisso com o horizonte da transformação social. O fato da prática ser polarizada por interesses de classe redobra o desafio de atentar-se para o espraiamento, por exemplo, de novas modalidades de intervenção que reiteram essa suposta neutralidade (sob o viés da negociação e conciliação de interesses).

\section{O Projeto Ético-Político frente à reatualização do conservadorismo.}

A disputa por projetos diferentes e antagônicos no âmbito da profissão acompanha a própria historicidade do Serviço Social, o que não nos possibilita tratar algumas manifestações como algo recente. Trata-se de um processo que vem ganhando consistência a partir das bases históricas regressivas e que vem possibilitando o recrudescimento do conservadorismo, sempre presente na profissão. Tal cenário se agrava na particularidade da profissão devido à precarização das condições de trabalho e da formação profissional. Conforme sabemos, a falta de preparo teórico e técnico fragiliza a formação de uma consciência politicamente crítica, motivando a busca por respostas pragmáticas, imediatistas, aparentemente uteis.

Nesse sentido, temos acompanhado a renovação e a reedição de práticas centradas em dinâmicas individuais, fragmentadas e focalizadas, com as mais diversas bases teóricas. Deparamo-nos com o resgate, a atualização e a busca de metodologias e técnicas conservadoras operadas no âmbito do que a profissão conheceu como Serviço Social Clínico, pelas influências conservadoras do "trabalho social com famílias" elaborado pela Política Nacional de Assistência Social e pelo avanço das atividades de conciliação e mediação na área sociojurídica, para citarmos alguns exemplos. Tais perspectivas, já presentes em outros momentos na profissão, hegemônicas nas décadas de 1950 e 1960, mobilizam elementos do positivismo e suas 
dissidências teóricas; ou seja, concepções pscicologizantes e moralistas expressas nos conceitos de anomia, patologia social e disfunção (LOWY, 2000), se adensam com elementos da pós-modernidade e vêm sendo incorporando-os ao arsenal teórico-metodológico do Serviço Social.

A denominada "conciliação de conflitos/mediação familiar", por exemplo, tal como nos informa o CRESS/SP (2016) vem alcançando significativa expressividade, sobretudo na área sociojurídico, e, o destaque recai no seu avanço do ponto de vista legal. Pelo menos no serviço público, tais práticas já foram incorporadas em legislações federais desde 2015. Conforme o Parecer Analítico da Assessoria Exclusiva do CRESS/SP recuperando a concepção de Barros (2013 apud CRESS/SP, 2016) tal atividade propõe-se a:

[...] [interferir] nas relações pessoais e coletivas, com recortes atuais no âmbito comercial, sócio-afetivo, judicial e extrajudicial que objetiva a introdução de um terceiro neutro, desvinculado de sua profissão de origem, capaz e habilitado no processo de conflito, visando a solução consensual de conflitos de interesses, mediante confecção de um Termo de Acordo que registre as tratativas alcançadas entre as partes, conforme o curso legal que se pretende dar ao feito (CRESS/SP, 2016, p. 61).

Ainda majoritariamente na área sociojurídica, teremos exemplos também de práticas de tutela e curatela sendo desenvolvidas por Assistentes Sociais ${ }^{8}$. Este encargo, normalmente, é atribuído pelo Juiz a um adulto capaz, para que se responsabilize na administração dos bens pessoais daqueles judicialmente declarados incapazes. Além das demandas pela inquirição de crianças, que têm como marco inicial o Depoimento sem Dano (DSD) ${ }^{9}$ e o Projeto de Lei que visa facilitar a adoção de crianças e, consequentemente, agilizar a destituição do poder familiar, em detrimento do investimento em ações que priorizem o direito à convivência com a família e a comunidade de origem.

Parece-nos que a prática mais alarmante, no sentido de mais claramente mobilizar elementos que nos remetem à gênese conservadora da profissão - baseada na doutrina social da igreja e, posteriormente, nas abordagens positivistas/funcionalistas - seja a prática do Coaching. De modo geral, o Coaching é apontado como um processo de desenvolvimento de competências na direção do alcance de metas de realização pessoal. Em uma concepção emprestada do mundo empresarial, o assistente social, enquanto um coach, conduziria e facilitaria esse processo da responsabilização do sujeito pela sua própria vida, ajudando-o a estabelecer ações em direção aos seus objetivos e metas.

No sentido de justificar essas práticas, estamos assistindo a uma tentativa de resgatar um arsenal categorial conservador e moralista, extraídos do Serviço Social tradicional. Além do mais, tais práticas revelam significativo estreitamento com um discurso funcionalista que culpabiliza o sujeito e desconsidera as questões de natureza estrutural, resultantes da dinâmica particular do capital no Brasil. Tais tendências - como a mediação familiar, que tem como pressuposto ético a neutralidade - confrontam um dos maiores avanços materializados pelo Projeto Profissional de ruptura com o conservadorismo. Qual seja, a desmistificação da pretensa neutralidade, que permitiu situar o Serviço Social na totalidade das relações sociais.

Nessa mesma direção, crescem as inserções profissionais no campo da denominada Comunidade Terapêutica ${ }^{10}$. Para além das contradições colocadas pelo próprio espaço institucional, pois os serviços prestados pelas CTs, em sua maioria, não reúnem condições de prestar um trabalho com qualidade e garantir estratégias de redução de danos, temos observado os profissionais incorporando os valores e a direção da própria instituição. Ou seja, uma atuação junto aos usuários pautada pela abstinência no processo de tratamento das pessoas que consomem psicoativos. Sendo comuns, ações de isolamento, proibicionismo e exploração da força de trabalho (laborterapia), conjuntamente à culpabilização, moralização a partir de tendências psicologizantes e higienistas. Somados a isso, temos o grave fator do tratamento pela "espiritualidade", considerado como "cura".

No caso das práticas terapêuticas, o CFESS (2008) faz uma ressalva no que concerne à dimensão subjetiva do trabalho do assistente social. Pontua que essa última não se constitui em atribuição privativa dos Assistentes Sociais, nem tampouco, o arcabouço teórico metodológico do Serviço Social atribui-Ihe competência para realizar um trabalho terapêutico amparado na psicologia e nos estudos clínicos. 
Podemos, deste modo, apontar que essas metodologias e técnicas sobrepõem-se ao Código de Ética e retomam aspectos da profissão já superados historicamente. Fortalecem o conservadorismo e revelam as atuais exigências de um profissional ainda mais tecnicista - voltado para meramente executar serviços, programas, projetos e benefícios, em uma perspectiva mais focalizada, de controle e culpabilização das/os usuárias/os (CFESS, 2017).

Contudo, importa-nos ainda ressaltar, assim como já revelam os documentos publicados pelas entidades representativas do Serviço Social, que a disseminação destas metodologias e técnicas conservadoras no Serviço Social não ocorrem isentas de contradições. Ainda que a conjuntura favoreça o espraiamento da ideologia restauradora que fundamenta essas abordagens; ao mesmo tempo, o acirramento da "questão social", a magnitude que vem alcançando - a ponto de ultrapassar barreiras territoriais (a exemplo da problemática questão da imigração e o seu alcance mundial) - limita a capacidade de respostas, aumenta a insatisfação da classe trabalhadora, a deterioração de suas condições de vida, e, portanto, dá margens ao acirramento dos conflitos sociais expressos nas lutas de classes. Nesta direção, a história repõe a centralidade da luta de classes, tornando-a mais nítida e necessária aos trabalhadores. E, ao mesmo tempo, ao pensarmos tais impactos para o exercício profissional - a partir da análise concreta das situações concretas - a escolha consciente pelo PEP se abre no horizonte, sendo favorecida - dentre outros elementos - pela produção de conhecimento crítica que construímos desde os anos 1970.

É, portanto, na direção das campanhas - como instrumento de enfretamento às tendências históricas conservadoras - que reafirmamos a defesa dos direitos da população e do trabalho profissional com qualidade. Esforços a partir dos quais desenvolveu-se o posicionamento crítico da categoria nos últimos 40 anos.

\section{Considerações finais}

O ato de escolher na sociedade capitalista o lado do trabalho/trabalhador em detrimento dos interesses do capital é uma opção ético-política assentada numa análise crítica da sociedade do capital, opção que só tem possibilidade de se objetivar - tornar-se realidade material -, a partir de uma práxis criativa, consciente, radicalmente crítica, reflexiva e coletiva - ou seja, uma práxis planejada e avaliada nas suas consequências -, tendo como parâmetro e finalidade os interesses históricos dos diferentes segmentos da classe trabalhadora (VASCONCELOS, 2015, p. 60, grifo do autor).

Parece-nos que desde os anos 1970/1980, na ocasião da ascensão das lutas democráticas para a promulgação da Constituição Federal de 1988 - no auge do Movimento de intenção de ruptura do Serviço Social (NETTO, 2004) - não vivenciamos um momento tão desafiador para a legitimação social do PEP. Naquele período, a aproximação da categoria com os movimentos sociais (organizados na luta pela transição democrática, depois de 20 anos de ditadura civil-militar) foi um fator determinante à construção de um novo perfil profissional.

O PEP, inaugurou, portanto, uma nova instrumentalidade profissional que vocalizou as bandeiras das classes subalternas, legitimando socialmente a direção de classe da intervenção dos Assistentes Sociais inscritas no Código de Ética de 1993 na defesa dos seguintes princípios: liberdade como valor ético central; defesa dos direitos humanos; ampliação e consolidação da cidadania; defesa da democracia, equidade e justiça social; eliminação de todas as formas de preconceito; vinculação do Projeto Profissional com o processo de construção de uma nova ordem societária sem dominação/exploração de classe, etnia e gênero; articulação com os movimentos sociais; pluralismo; aprimoramento intelectual; exercício profissional isento de qualquer tipo de discriminação (BRASIL, 2012).

Hoje, diferentemente do que ocorreu nos anos 1990, no auge do neoliberalismo no Brasil - a ameaça neoliberal à hegemonia do PEP (NETTO, 1999) - o contexto de acirramento das lutas sociais, torna mais evidente a capacidade de implementação e aprofundamento desse Projeto Profissional, abafando aquelas 
vozes que atribuíam um suposto caráter de atraso ao projeto. A nosso ver, há um redirecionamento, portanto, do teor dos questionamentos aos valores do PEP. Além disso, conforme chamou-nos a atenção Netto, nos últimos anos não tivemos questionamentos diretos e significativos ao Projeto Ético Político, pelo contrário:

[...] a forma de pô-lo em causa não tem consistido em enfrentá-lo abertamente: consiste em proclamá-lo e invocá-lo como se fora um projeto cujo pluralismo não tem fronteiras e que, portanto, comporta ilimitadas possibilidades de concretização teórica e prática (NETTO, 2016, p. 66).

Acreditamos que, a particularidade deste momento histórico, pode favorecer o projeto ao tornar mais evidente o estreitamento dos seus valores com as exigências genéricas da humanidade no que concerne a sua correlação com a ética. Neste sentido, o Código de ética profissional, a Lei de Regulamentação da profissão e as diretrizes da formação profissional condensam e fortalecem aquelas mesmas bandeiras de liberdade ovacionadas pelos trabalhadores. Como também as entidades profissionais. Afinal, os avanços e conquistas também foram possíveis diante da organização política da categoria, a qual destacamos no presente texto o conjunto CFESS/CRESS. Nas trilhas apontadas por Ramos e Santos (2016, p. 218).

Compreendemos aqui a organização política da categoria de assistentes sociais como uma das condições históricas primordiais para viabilizar a capacidade de projetar coletivamente caminhos estratégicos para a profissão e para a sociedade, bem como ferramenta que possibilita a ampliação da politização de diversos segmentos da classe trabalhadora que sentem/convivem com as múltiplas formas de exploração e opressão engendradas nesta sociabilidade.

Importante ressaltar que, a conjuntura da primeira década dos anos 2000, sob a égide neodesenvolvimentista, criou um ambiente propício à disseminação de um ideário de conciliação de classe. Essa dinâmica, por sua vez, também foi funcional ao questionamento do conteúdo do Código de ética à medida que os projetos conciliatórios vislumbram a possibilidade de vida digna no capitalismo. Vale destacar que, as disputas por hegemonia entre os setores da profissão, mais claras recentemente, não são entendidas aqui como manifestações recentes. Trata-se de um processo que vem adquirindo consistência a partir de bases históricas concretas, aguçadas diante da crise estrutural do sistema do capital, na qual vem se expressando na profissão nos órgãos representativos - basta nos atentarmos para as disputas de chapas da última eleição dos CRESS - mas também nas produções teóricas e formação profissional.

Dialeticamente, o atual cenário de agudização da luta de classes pode direcionar as reflexões acerca do Código de ética no sentido oposto: quer seja, potencializando suas possibilidades de efetivação, uma vez que, mais claramente posta aos olhos da classe trabalhadora, a dinâmica capitalista opera em desalinho ao enriquecimento humano genérico, a emancipação humana. Ou seja, o resultado da forma particular como funciona a acumulação capitalista vem alarmando a humanidade acerca do seu risco de existência - o ataque aos direitos conquistados, os crimes ambientais, os conflitos armados, o fortalecimento do conservadorismo, a miséria, a fome, a pobreza e sua proporção alarmante.

Sobre esse último aspecto, vale recuperar as fecundas contribuições de Lessa (2015) que, ao abordar a ética em uma perspectiva ontológica, conclui a sua irrealização no sistema do capital, como consequência imediata da subsunção da humanidade ao fetichismo da mercadoria. Isto porque, na síntese desse autor, o capital produz uma sociabilidade essencialmente moralista, rebaixada às necessidades e possibilidades do individualismo burguês. A existência da propriedade privada constrange os indivíduos contemporâneos a resolverem os seus dilemas e explorarem as possibilidades humano-genéricas do ponto de vista de seus interesses pessoais. Ou seja, o modo de produção capitalista opera no rebaixamento das necessidades genéricas à miserabilidade do individualismo da propriedade privada burguesa. Neste sentido, impossibilita a elevação da personalidade dos indivíduos a sua genericidade, na qual a realização pessoal tem como condição a realização de todos (LESSA, 2015).

Fica claro que o espraiamento dessa moral individualista burguesa ofusca os valores éticos fundamentados na centralidade da liberdade - na perspectiva em que estão inscritos no nosso Código de 
Ética - tornando-os irrealizáveis. Contudo, a ideia da impossibilidade de realização plena de qualquer ideal ético em uma sociedade cuja essência é a propriedade privada, de nenhuma maneira anula a intencionalidade revolucionária que envolve o chamado Projeto Ético-Político do Serviço Social (LESSA, 2005).

É neste sentido que o Serviço Social assumiu no seu PEP uma perspectiva ontológica, na qual a ética é entendida enquanto mediação valorativa que expressa as necessidades e possibilidades humanogenéricas para que os indivíduos as assumam como suas. Um complexo social cuja função é a elevação dos indivíduos a uma existência genérica e, não como ocorre com a moral burguesa, o rebaixamento do genérico à propriedade privada. Concentra-se justamente neste aspecto, a "validade histórica do referido projeto profissional".

Por último, resta-nos enfatizar que, como vimos, a hegemonia do PEP, não abafou vozes dissonantes que questionavam as suas possibilidades de efetivação e apontavam para um potencial utópico, no sentido que o senso comum atribui ao termo: fantasioso, ilusório, impossível! Essas vozes aumentaram sobretudo no decurso dos anos 1990 e 2000. No entanto, concordamos com Vasconcelos (2015, p. 74) quando a autora destaca que para "[...] os assistentes sociais que tomam o projeto do Serviço Social como referência, ao atuarem como indivíduos/profissionais nessa direção, cabe aqui não confundir projeto profissional utópico/ inviável/impossível com projeto profissional exigente/trabalhoso/árduo".

Hoje, a história vem evidenciando a total coerência do nosso PEP com as bandeiras que estão sendo levantadas pela classe trabalhadora na luta contra a supressão de direitos. Tal fato, impulsiona o fortalecimento da direção profissional estreita com um projeto socialista de transformação social: ocupar as ruas, aderir as greves e paralisações, engrossar a luta! Pensamos que essas tenham sido as mensagens centrais das campanhas comemorativas do dia do Assistente Social lançadas no maio de 2017 e 2018.

Assim, compreendendo o Serviço Social a partir de sua inserção nas relações sociais, participando da reprodução social (IAMAMOTO, 2005), os argumentos aqui dispostos, organizam-se no sentido de contribuir para as reflexões que problematizam as condições a serem construídas coletivamente para a efetivação de uma intervenção em uma perspectiva de classe, na defesa dos direitos da classe trabalhadora.

\section{Referências}

ABREU, M. M.; CARDOSO, F. G. Mobilização social e práticas educativas. In: ABEPSS; CFESS (org.). Serviço Social: direitos sociais e competências profissionais. Brasília: Cfess/Abepss, UnB, 2009. p. 593-608.

BRASIL. Código de ética do/a assistente social. Lei 8.662/93 de regulamentação da profissão. 10. ed. Brasília: Conselho Federal de Serviço Social, 2012.

CONFEDERAÇÃO NACIONAL DAS INDÚSTRIAS (CNI). Agenda para o Brasil sair da crise 2016-2018: Evolução após um ano. Março 2017. Disponível em: http://www. portaldaindustria.com.br/publicacoes/2016/4/agenda-para-o-brasil-sair-dacrise-2016-2018/ . Acesso em: 20 maio 2017. https://doi.org/10.5151/9788580392821-02

CONSELHO FEDERAL DE SERVIÇO SOCIAL (CFESS). 'Cracolândia'? O que o Serviço tem a ver com isso? Série conjuntura e impacto no trabalho profissional. CFESS Manifesta, Brasília, jun. 2017a. https://doi.org/10.1590/0101-6628.140

CONSELHO FEDERAL DE SERVIÇO SOCIAL (CFESS). Serviço Social é notícia - Informativo do Conjunto CFESS-CRESS, ano 3, n. 3, maio 2017. https://doi.org/10.26512/ser_social.v14i30.12989

CONSELHO FEDERAL DE SERVIÇO SOCIAL (CFESS). Práticas terapêuticas no âmbito do Serviço Social: subsídios para aprofundamento do estudo. Comissão de Fiscalização/COFI, aprovado pelo CFESS, jun 2008. https://doi.org/ 10.1590/0101-6628.140

CONSELHO REGIONAL DE SERVIÇO SOCIAL/CRESS/SP. Posicionamento preliminar sobre Serviço Social e mediação de conflitos. São Paulo, 2016.

GUERRA, Yolanda. A instrumentalidade do Serviço Social. 3. ed. São Paulo: Cortez, 2002.

IAMAMOTO, M.; CARVALHO, R. de. Relações sociais e Serviço Social no Brasil: esboço de uma interpretação históricometodológica. 18. ed. São Paulo: Cortez, 2005. 
LESSA, Sérgio. Luckács: ética e política. Observações acerca dos fundamentos ontológicos da ética e da política. São Paulo: Instituto Luckács, 2015.

LESSA, Sérgio. Ética, política e Serviço Social. Katálisys, Florianópolis, v. 8, n. 2, p. 256-266, jul./dez. 2005.

LOWY, Michael. As aventuras de Karl Marx contra o barão de Munchhausen: marxismo e positivismo na sociologia do conhecimento. São Paulo: Cortez, 2000.

MARX, K. O capital: crítica da economia política. Livro I: o processo de produção do capital. Trad. Rubens Enderle. São Paulo: Boitempo, 2013.

MÉSZÁROS, Istvan. A crise estrutural do capital. István Mészáros. São Paulo: Boitempo, 2009. https://doi.org/10.12957/ rep.2016.25393

NETTO, J. P. Ditadura e Serviço Social. 7. ed. São Paulo: Cortez, 2004.

NETTO, J. P. A construção do projeto ético-político contemporâneo. In: NETTO, J. P. Capacitação em Serviço Social e Política Social. Módulo 1. Brasília: CEAD/ABEPSS/CFESS, 1999.

NETTO, J. P. Para uma história nova do Serviço Social no Brasil. In: SILVA, Maria Liduína de Oliveira e (org.). Serviço Social no Brasil: história de resistências e de ruptura com o conservadorismo. São Paulo. Cortez, 2016. https://doi.org/10.1590/0101-6628.080

RAMOS, S. R.; SANTOS, S. M. M. Projeto profissional e organização política do Serviço Social brasileiro: lições históricas e lutas contemporâneas. In: SILVA, M. L. O. (org.). Serviço Social no Brasil: história de resistências e de ruptura com o conservadorismo. São Paulo: Cortez. 2016. https://doi.org/10.1590/0101-6628.080

VASCONCELOS, A. M. A/O Assistente Social na Luta de Classes: Projeto Profissional e Mediações Teórico-Práticas. São Paulo: Cortez, 2015.

\section{Notas}

${ }^{1}$ Conselho Federal de Serviço Social (CFESS) e Conselho Regional de Serviço Social (CRESS).

2 Ao exemplo da maior megalópole do Brasil, a cidade de São Paulo, tivemos a conduta do ex-governador Geraldo Alckmim nas ações de "higienização" da Cracolândia, no dia 21 de maio de 2017, que implicou em verdadeira "varredura" dos indivíduos dependentes de substâncias psicoativas, sob atuação violenta da tropa de choque. Um claro exemplo do despreparo para lidar com a questão das "drogas" como um problema de saúde pública e não na perspectiva de culpabilização e criminalização do usuário. Essa ação truculenta do Estado brasileiro foi denunciada pelo CFESS Manifesta, lançado em junho de 2017. Ver CFESS (2017a).

${ }^{3}$ Vale ressaltar, conforme apontou Vasconcelos (2015, p. 238), que na direção do PEP "[...] não basta tomar o trabalho ou o compromisso com a classe trabalhadora como referência, mas agir tendo em vista favorecê-la, na busca de imposição de limites do capital".

${ }^{4}$ Referimo-nos, sobretudo, à rede Globo enquanto um dos principais veículos de socialização de informações - um aparelho privado de hegemonia, na acepção gramsciana - que atua na construção de um consenso social em torno dos interesses dos grandes capitais (e, não poderia ser diferente sendo esta emissora financiada pelos banqueiros, empreiteiros e empresários).

${ }^{5}$ Dentre as medidas que ganharam maior expressividade e unificaram a classe trabalhadora nas mobilizações mais recentes, destacamos: a PEC 241/EC 95 de 2016 do congelamento dos gastos públicos, o PL no 193/2016, conhecido como “Escola sem Partido", a MP no 746/2016 da reforma do Ensino Médio, a Lei no 13.415/2017 que trata do novo ensino médio, a PEC 287/2016 da Reforma da Previdência, os projetos de terceirização e prevalência do negociado sobre o legislado.

${ }^{6}$ Este objetivo vem sendo perseguido pelo Conjunto CFESS/CRESS mediante a publicação, por exemplo, do "CFESS Manifesta" - lançado sempre que a categoria avalia a necessidade de posicionamento coletivo acerca de análises conjunturais e de lutas sociais. Conferir a aba publicações no site: http://www.cfess.org.br. Mais recentemente, o CFESS também lançou a série "Conjuntura e Impacto no Trabalho profissional" que apresenta dentro do CFESS Manifesta, reflexões que dialogam com a categoria sobre os desafios da intervenção profissional diante da conjuntura.

7 Conforme chamou-nos atenção Vasconcelos: "ao respondermos mecânica e acriticamente o chamado político da burguesia [ressaltando o óbvio: tudo o que supõe um projeto societário é política e a burguesia luta e gasta ferozmente na busca de manter seu projeto como hegemônico] para gerenciar acriticamente a miséria e a pobreza e/ou para controlar os trabalhadores inseridos ou não no mercado de trabalho, o exercício profissional resulta somente em despolitização, desmobilização, desorganização e em mais um instrumento de destruição de subjetividades sob o comando da burguesia/grande capital e, queiramos ou não, estamos fazendo política, porque, consciente ou inconscientemente, estamos fazendo escolhas. Negar isso é negar o exercício profissional como um ato político permeado por escolhas, favorecendo a ideia de que na técnica/tecnologia está a resposta para tudo. Ou seja, bastaria um exercício profissional "tecnicamente qualificado", mas "esvaziado de conteúdo" (VASCONCELOS, 2015, p. 244).

${ }^{8}$ Esta temática foi abordada no Seminário intitulado: "O Serviço Social frente aos encantos da pós-modernidade", realizado pelo CRESS/ SP, no ano de 2016. Parte da programação do seminário contou com a socialização, pelos grupos de trabalhos, dos debates realizados 
acerca do posicionamento da profissão, assim como as definições e principais expressões destas "novas" metodologias/atividades de caráter pós-moderno na intervenção profissional. A cobertura completa encontra-se disponível em: https://www.youtube.com/channel/ UC6UPLiPKFgMfPE8mM8Tc-dQ. Acesso em: 18 maio 2017.

${ }^{9}$ Ver CFESS Manifesta - Série Conjuntura e Impacto no Trabalho Profissional: Lei n.o 13.431/2017 e o Depoimento Sem Dano.

${ }^{10} \mathrm{Em}$ agosto de 2018, foi lançado pelo CFESS o relatório de fiscalização: Serviço Social e a Inserção de Assistentes Sociais nas Comunidades Terapêuticas no Brasil. Trata-se de um relatório de fiscalização que aponta graves problemas na inserção de assistentes sociais nas Comunidades Terapêuticas (CTs). O documento elaborado pela COFI/CFESS a partir de visitas de Orientação e Fiscalização realizadas pelos CRESS reforça que as CTs estão na contramão do que preconiza a Reforma Psiquiátrica e o Projeto Ético-Político Profissional. Disponível em: http://www.cfess.org.br/arquivos/RelatorioCFESS-ComunidadesTerapeuticas2018-Site.pdf. Acesso em: fev. 2019.

Recebido em: 19/2/2019.

Aprovado em: 9/4/2019.

Publicado em: 10/10/2019.

Correspondência para:

Clara Martins do Nascimento

Universidade Federal de Santa Catarina

Rua Eng. Agronômico Andrei Cristian Ferreira, s/n - Trindade

88040-900, Florianópolis, SC, Brasil

\section{Autores:}

CLARA MARTINS dO NASCIMENTO

Mestra em Serviço Social pela Universidade Federal de Pernambuco (UFPE), Recife, PE, Brasil.

Doutoranda em Serviço Social pela Universidade Federal de Santa Catarina (PPGSS/UFSC), Florianópolis, SC, Brasil.

Professora assistente do Curso de Serviço Social da Universidade de Pernambuco (UPE),

Campus Mata Sul, Palmares, PE, Brasil.

Orcid: https://orcid.org/0000-0002-9810-2712

E-mail: asclara88@gmail.com

Claudio Henrique Miranda Horst

Doutor em Serviço Social pela Universidade Federal de Santa Catarina (PGSS/UFSC), Florianópolis, SC, Brasil.

Docente na Universidade Federal de Ouro Preto, Departamento de Serviço Social (DESSO/UFOP), Mariana, MG, Brasil.

Orcid: https://orcid.org/0000-0002-2226-4520

E-mail: claudiovasques1@hotmail.com

Endereço: Universidade Federal de Ouro Preto

Rua Diogo de Vasconcelos, 122 - Pilar - 35400-000, Ouro Preto, MG, Brasil 